\title{
Ultrapassando fronteiras: trajetórias de ascensão de militantes brasileiros no sindicalismo transnacional
}

\section{Resumo}

Este artigo pretende analisar o processo por meio do qual, nas últimas duas décadas, sindicalistas brasileiros se engajaram na construção de uma "agenda global" de defesa dos direitos dos trabalhadores. Mais especificamente, interessa-nos compreender quais são as condições sociais de acesso às organizações sindicais internacionais para discutir como a militância, no plano global, tem se convertido em um caminho, até então improvável, para lideranças nacionais. Para tanto, lançaremos mão da análise de trajetórias de sindicalistas metalúrgicos brasileiros que ocupam cargos na federação sindical internacional IndustriALL. A análise dos dados indica que as trajetórias sindicais internacionais se têm sustentado sobre um conjunto de capitais e um habitus militante específicos, articulados com o desenvolvimento de variáveis objetivas, particulares do caso brasileiro.

Palavras-chave: Sindicatos. Internacionalização. Habitus. Engajamento. Militância.

\footnotetext{
* Universidade Federal da Paraíba, Brasil.

** Universidade de São Paulo, Brasil.
} 


\section{Beyond boundaries: histories of the rise of Brazilian militants in the transnational trade union activism}

\section{Abstract}

This article aims to analyze the process through which, in the last two decades, Brazilian trade unionists have engaged in the construction of a "global agenda" for advocating for workers' rights. More specifically, we seek to understand the social conditions of access to international trade union organizations, in order to find out how the global militancy has become an unforeseen path for national union leaders. To this end, we analyze the leadership paths of Brazilian metalworkers who occupy positions in the international trade union federation IndustriALL. The analysis of the data indicates that the paths followed by these international union leaders have been based on social capital and specific militant habitus combined with the development of objective variables that are peculiar to the Brazilian case. Keywords: Trade unions. Internationalization. Habitus. Engagement. Militancy.

\section{Introdução}

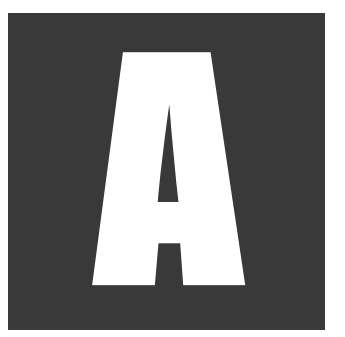

inserção internacional de militantes do campo da esquerda e do movimento operário brasileiro data do início do século XX. No entanto, o fenômeno que se convencionou chamar de globalização alterou de modo importante o sentido, a forma e os objetivos dessa inserção, conduzindo a um quadro no qual sindicalistas, de diferentes categorias profissionais, ascenderam a cargos e funções de destaque em organizações sindicais transnacionais (Rombaldi, 2012, 2016; Tomizaki, 2013a). Buscando compreender processos sociais que, por vezes, se desenvolvem silenciosamente e, quando eclodem, aparentam ser "improváveis", neste artigo, analisaremos o processo por meio do qual, nas últimas duas décadas, sindicalistas brasileiros se engajaram em torno de uma "agenda global" de defesa dos 
direitos dos trabalhadores. Mais especificamente, interessa-nos discutir as condições sociais de acesso a organizações sindicais internacionais, o perfil e a atuação desses sindicalistas no plano global e nacional' ${ }^{1}$.

Para tanto, lançaremos mão da análise de trajetórias de sindicalistas metalúrgicos brasileiros que ocupam cargos na federação sindical internacional IndustriALL, buscando responder às seguintes interrogações: em que condições sociais essas lideranças se internacionalizaram ou que tipo de trajetórias familiares, escolares, profissionais e políticas possibilitaram sua circulação internacional? Essa "nova" dimensão da ação sindical exigiria capitais políticos específicos²? E, finalmente, quais são os efeitos da atuação desses dirigentes no movimento sindical nacional e internacional?

Para realizar essa discussão, faremos uso de uma abordagem sociobiográfica que permite compreender a maneira como disposições individuais encontram as condições de sua realização em determinadas conjunturas econômicas, sociais e políticas. Tal análise exige a reconstituição e a comparação de histórias individuais e coletivas, a articulação entre a abordagem macrossocial e a escala singular. A partir disso, utilizamos dados de caráter biográfico e prosopográfico, objetivando "reunir as duas pontas" e permitir a análise de trajetórias de militantes na interseção com a trajetória de grupos sociais nos quais estão inseridos (Fillieule; Pudal,

\footnotetext{
${ }^{1}$ Os dados que serão discutidos neste artigo foram coletados no âmbito de duas pesquisas financiadas, pela Coordenação de Aperfeiçoamento Pessoal de Nível Superior (CAPES) e pela Fundação de Amparo à Pesquisa do Estado de São Paulo (FAPESP). Tratam-se, respectivamente, das pesquisas: $O$ transnacional ante as fronteiras nacionais: a ação sindical e as condições sociais de acesso aos espaços sindicais internacionais (CAPES, 2008), de Maurício Rombaldi; e Socialização e política: um estudo sobre a formação de disposições para a militância entre membros da classe operária (Processo FAPESP: 2009/11542-3) de Kimi Tomizaki

${ }^{2} \mathrm{O}$ capital político refere-se a uma forma de capital simbólico fundado na notoriedade e na popularidade, que é, em geral, como o capital cultural, herdado ou concedido a um indivíduo por um determinado grupo. O capital militante, por sua vez, refere-se a um capital específico que deriva do político. Trata-se de um conjunto de técnicas e saberes que orientam a ação no espaço político e são resultado de uma aprendizagem ocorrida na própria experiência de militância (Cf: Matoni; Poupeau, 2004 e Bourdieu, 2005).
} 
2010; Leclercq; Pagis, 2011; Boulland, 2014). Com relação a isto, Bourdieu (1986, p.71) observa:

Tentar compreender uma vida como uma série única e, por si só, suficiente de acontecimentos sucessivos, sem outra ligação que a vinculação a um 'sujeito' cuja única constância é a do nome próprio, é quase tão absurdo quanto tentar explicar um trajeto no metrô sem levar em conta a estrutura da rede, isto é, a matriz das relações objetivas entre as diversas estações. Os acontecimentos biográficos definem-se antes como alocações e como deslocamentos no espaço social, isto é, mais precisamente, nos diferentes estados sucessivos da estrutura da distribuição dos diferentes tipos de capital que estão em jogo no campo considerado. É evidente que o sentido dos movimentos que levam de uma posição a outra (...) define-se na relação objetiva entre o sentido dessas posições no momento considerado, no interior de um espaço orientado. Isto é, não podemos compreender uma trajetória (...) a menos que tenhamos previamente construído os estados sucessivos do campo no qual ele se desenrolou.

Nesse sentido, a presente análise se pautou no princípio de que os indivíduos são resultado de processos de socialização que, por sua vez, são determinados ou condicionados, inicialmente, pelas condições objetivas do "lugar social" ocupado pelos indivíduos em função de seus nascimentos e, posteriormente, pelos espaços nos quais esses mesmos indivíduos puderam circular. Desse modo, para o exercício de investigação sociológica desenvolvido aqui, apresentaremos duas biografias de sindicalistas com trajetórias de destaque no sindicalismo internacional, que são paradigmáticas para o entendimento dos mecanismos de acesso a tais espaços. Os dados analisados foram coletados por meio de entrevistas realizadas entre os anos de 2008 e 2016 e da consulta a material disponibilizado pela imprensa sindical. 
Como já discutido em artigo anterior, partimos da premissa de que:

O trabalho sindical, como todo trabalho ligado ao campo político, constitui uma ação instável que requer um aprendizado do conjunto de regras de funcionamento desse campo específico. Pode-se dizer que o acúmulo de aprendizagens específicas conjugadas a certas características pessoais dos sindicalistas constitui uma espécie de capital militante e político, que permite ao seu detentor ocupar um espaço legítimo no interior da entidade da qual participa. [...] Mas é preciso sublinhar que os "conteúdos" que compõem essa posição de legitimidade podem ser alterados por transformações mais amplas que atingem os espaços políticos - tais como as mudanças na ordem econômica mundial ou nacional -, o que exige novas aprendizagens dos seus participantes (Tomizaki; Rombaldi, 2009, p. 96-97).

Nossa hipótese é a de que os sindicalistas que circulam e se inserem nas esferas internacionais o fazem por meio da mobilização de variados capitais (simbólicos, políticos, escolares e de redes de relações), que, por sua vez, estão necessariamente associados a um habitus militante específico, que os diferencia dos sindicalistas que constroem suas carreiras exclusivamente no âmbito local ou nacional. Sobre o conceito de habitus, Bourdieu (2009, p. 90) observa:

Produto da história, o habitus produz as práticas, individuais e coletivas, portanto, da história, conforme aos esquemas engendrados pela história; ele garante a presença ativa das experiências passadas que, depositadas em cada organismo sob a forma de esquemas de percepção, de pensamento e de ação, tendem, de forma mais segura que todas as regras formais e que todas as normas explícitas, a garantir a conformidade das práticas e sua constância ao longo do tempo. (...) O habitus como toda arte de inventar, é o que permite produzir práticas em número infinito, relativamente imprevisíveis (como as situações correspondentes), mas limitadas, todavia, em sua diversidade. 
Na obra de Bourdieu, a noção de habitus desempenha um papel de mediação entre o individual e o social, mais especificamente, refere-se à "subjetividade socializada", ou seja, a uma estrutura de personalidade constituída a partir das marcas legadas pela experiência biográfica em um dado contexto social. As práticas sociais, por sua vez, são geradas no encontro entre as estruturas incorporadas e as estruturas objetivas de um campo específico no qual o agente precisa atuar em um dado momento. A questão é que dificilmente as condições objetivas nas quais o habitus foi formado se repetirão, de modo que os agentes precisam passar a atuar em campos outros ou no mesmo campo renovado em suas regras de funcionamento. É nesse momento que a capacidade "inventiva" do habitus se expressa, adaptando-se à nova realidade ao criar respostas inovadoras - e, até mesmo, improváveis -, circunscritas, de algum modo, pelos limites do próprio habitus e dos seus princípios geradores. Em resumo, o habitus é durável, apesar de mutável (Peters, 2009). Considerando isso, este artigo analisa como as trajetórias sociais de determinados sindicalistas foram capazes de constituir um habitus que, por responder às expectativas e exigências do espaço sindical internacional, Ihes garantiu condições de inserção e ascensão a posições de destaque, até então improváveis às lideranças brasileiras.

\section{Internacionalização da luta operária e o futuro do sindicalismo: algumas reflexões}

Os desafios impostos pelos processos de globalização e pela redução da capacidade de os Estados agirem como reguladores das relações de trabalho têm sido amplamente tratados como princípios explicativos ao entendimento das dificuldades enfrentadas pelos sindicatos na negociação com o patronato e na mobilização de suas bases. É preciso considerar, 
em primeiro lugar, que o expressivo crescimento de Empresas Transnacionais (ETNs) ${ }^{3}$ nas últimas décadas tem criado obstáculos significativos para os sindicatos, que passam a desenvolver pautas de reivindicações e a negociar acordos, seja com gerências estrangeiras, seja com gestores nacionais com limitada capacidade para tomada de decisões. Além disso, análises assinalam que a globalização produtiva vem acompanhada do crescimento de situações de trabalho temporário, de altos índices de rotatividade no emprego e da dispersão geográfica de empresas - cada vez mais livres para deslocar-se entre regiões e países com regulamentação trabalhista mais frágil e com menor ou nenhuma tradição de organização dos trabalhadores (Harvey, 1993; Boltanski; Chiapello, 2009). Em decorrência desse processo, no plano político, encontram-se conflitos simbólicos-geracionais entre trabalhadores e lideranças sindicais formados em períodos distintos no que tange à estabilidade das relações de trabalho, o que imprime desafios crescentes à interlocução entre jovens e velhos (Beaud; Pialoux, 2009).

Nesse contexto, Ramalho (2014) avalia que a desorientação da ação sindical provocada pela incapacidade de os governos resistirem às forças da globalização econômica e pela transnacionalização de empresas traria questionamentos sobre a capacidade de os sindicatos se manterem como instituições de representação efetiva dos trabalhadores. Assim, a articulação de trabalhadores em redes internacionais estaria explicitando novas formas organizativas, bem como novos padrões de regulação do trabalho, o que permitiria considerar um paulatino desenvolvimento de práticas sindicais para além das fronteiras nacionais como uma alternativa concreta ao enfrentamento da atual conjuntura. O autor observa, ainda, que os "trabalhadores organizados em sindicatos e comissões de fábrica não

\footnotetext{
${ }^{3}$ Relatório da UNCTAD (2008) aponta para o expressivo crescimento global de ETNs, em que se identificaram mais de 790.000 filiais até o ano de 2007. Passados quase dez anos desse relatório, não se verificam indícios de reversão desta tendência.
} 
podem ficar apenas restritos às questões salariais", mas que se faz necessário ampliar suas perspectivas de ação visando a propiciar a "formação de uma identidade social através do trabalho" (Ramalho, 2014, p. 40-41).

No mesmo sentido, analistas têm desenvolvido a tese de que as dificuldades e os obstáculos que a globalização econômica impõe à organização dos trabalhadores e dos seus sindicatos também poderiam revelar possibilidades para o movimento sindical, na medida em que seriam estabelecidos novos mapas corporativos que permitiriam superar lógicas de militância circunscritas a identidades e setores específicos (Evans, 2010; Munck, 2010). Pries e Seeliger (2013), da mesma forma, consideram que as últimas décadas têm sido marcadas por um processo de desenvolvimento institucional direcionado à constituição de novas formas de regulação das relações de trabalho - organizações sindicais internacionais, Acordos Marco Internacionais (AMI), Global Compacts, comissões mundiais de trabalhadores em ETNs etc. No Brasil, essa tendência pode ser observada por meio da emergência de redes sindicais internacionais atuantes no país e que aparentam impactar positivamente as ações sindicais de âmbito local e nacional, uma vez que contribuem para a negociação de benefícios para os trabalhadores locais (Mello e Silva et al., 2015).

A articulação de trabalhadores para além das fronteiras nacionais pode ser observada de diversas formas: (i) a participação sindical em fóruns promovidos pela Organização Internacional do Trabalho (OIT); (ii) a participação nas negociações sobre as definições dos moldes de institucionalização de mecanismos multilaterais de governança, como no caso do MERCOSUL ; ; (iii) o estabelecimento de articulações bilaterais entre entidades sindicais de diferentes países; (iv) as redes sindicais em ETNs; e (v) os comitês mundiais de trabalhadores de em-presas, observados,

\footnotetext{
${ }^{4}$ Com relação à participação sindical nos debates do MERCOSUL, ver o caso do Grupo de Trabalho-10 e as propostas das comissões sindicais metalúrgicas para temas comerciais e produtivos, como a da Tarifa Externa Comum, de 1994.
} 
sobretudo, em empresas alemãs como a Mercedes-Benz e a Volkswagen. Além disso, em se tratando de "arranjos" políticos-institucionais no ambiente internacional, destacam-se as confederações sindicais internacionais (CSIs) e as federações sindicais internacionais (FSIs) ${ }^{5}$.

Esses dois últimos grupos compõem o quadro institucional dos organismos sindicais internacionais. As CSIs constituem-se como organizações internacionais que agrupam as centrais sindicais nacionais, tal o caso da homônima Confederação Sindical Internacional $(\mathrm{CSI})^{6}$ e o seu braço no continente americano, a Confederação Sindical das Américas (CSA). Essas entidades são marcadas pelo escopo de ação direcionada, principalmente, à representação política junto a espaços de debate sobre o comércio regional ou a organismos internacionais, tal como OIT, ONU e suas agências. No caso das FSIs, elas filiam organizações na forma de sindicatos, federações e confederações nacionais vinculadas a determinados setores econômicos e, embora exerçam representação política semelhante à das CSIs, direcionam suas ações, fundamentalmente, para a defesa dos direitos de trabalhadores de categorias econômicas específicas. Tornam-se, assim, um veículo direto para negociação e pressão sobre as ETNs.

Tais estruturas sindicais estabelecem-se como referências à constituição do campo sindical internacional, visto que valorizam pautas e estratégias próprias à "arena global", como no caso das campanhas direcionadas à regulação das relações de trabalho em megaeventos como as Olimpíadas e a Copa do Mundo de futebol (Rombaldi, 2014), ou nos casos de combate ao dumping social, caracterizado pelo emprego de trabalhadores em situação de vulnerabilidade. Além disso, as FSIs e as CSIs atuam como instituições para o exercício regular de práticas internacionais, por disporem de estruturas definidas, administrarem projetos em conjunto

\footnotetext{
${ }^{5}$ Em inglês, as Global Union Federations (GUF's).

${ }^{6}$ Em inglês, International Trade Union Confederation (ITUC).
} 
com organismos cooperantes, buscarem fontes de financiamento próprio e desenvolverem planos estratégicos.

Esse cenário, portanto, corresponde a uma institucionalização da ordem sindical internacional, em que CSIs e FSIs constituem um espaço objetivo para a interação sindical tanto no nível internacional como no nacional. No segundo, em especial, destacam-se estratégias ${ }^{7}$ capazes de reunir organizações filiadas com posicionamentos políticos divergentes, tal o caso de sindicatos da CUT e da Força Sindical no interior da IndustriALL. Assim, não seria exagero afirmar que a interseção entre os níveis produtivos local e global tem conduzido também à interseção entre organizações sindicais nacionais e internacionais. Tal confluência sindical é amplificada na medida em que essas estruturas passam a operar com pautas amplas e gerais que tratam de pontos de convergência ${ }^{8}$ entre os mais variados sindicatos, o que implica a legitimação de um espaço de debate e da conformação de estratégias globais.

A atuação nesse espaço sindical internacional institucionalizado exige habilidades específicas tanto de técnicos e assessores quanto das suas lideranças. Isso conduziu à consolidação de staff permanentes, constituídos em função de suas aptidões para organização, planejamento e execução regular de campanhas globais, reuniões entre sindicatos de diferentes países, organização de visitas de delegações em distintos países, comunicação com afiliados, promoção de cursos de formação em temas correlatos etc. Da parte das lideranças, demandam-se, cada vez mais, competências que possibilitem o trânsito junto a agências de cooperação sindical internacional - em que se negociam o financiamento de projetos e assuas prioridades em termos de objetivos e resultados -, gerências

\footnotetext{
${ }^{7}$ Dois exemplos significativos dessas estratégias são as campanhas direcionadas a trabalhadores em megaeventos esportivos, citadas acima, e as negociações ao redor de AMls junto a ETNs. ${ }^{8}$ Os AMIs, por exemplo, são acordos internacionais estabelecidos junto a ETNs em que, de forma geral, pautam-se exclusivamente temas relativos ao respeito às leis nacionais, bem como às convenções internacionais estabelecidas na OIT.
} 
mundiais de ETNs, representantes de governos na ONU, OIT e outros stakeholders.

No que diz respeito à inserção de sindicatos nacionais na arena sindical global como alternativa para a superação dos desafios locais, autores têm apontado para a dificuldade em percebê-la como uma tendência para o futuro do sindicalismo mundial. Apesar do sucesso alcançado com a adoção de campanhas internacionais em determinados países, não há evidências que apontem para a continuidade dessas práticas por parte das organizações locais (Rombaldi, 2014). Isso significa que, tão logo esse tipo de ação tenha sido concluído, as organizações podem tender a voltar-se para a priorização de políticas de âmbito local, o que seria um obstáculo à internacionalização sindical (Costa, 2005).

No caso brasileiro, ainda assim, o protagonismo de sindicalistas da CUT no plano internacional tem crescido de forma expressiva, em razão da progressiva valorização de sua política de relações internacionais. Conforme observamos a seguir, ainda que tal valorização date da fundação dessa central sindical, no contexto atual, ela tem se intensificado diante dos desafios impostos pela globalização e pode ser observada por meio de diversas iniciativas, em que se destacam: a criação do Instituto de Cooperação Internacional da central, em 2012, o apoio à constituição de redes sindicais em ETNs de diversos setores econômico, o expressivo apoio à Confederação Sindical das Américas - em que a central se destaca por ser a maior contribuinte em valores de cotas de filiação - e a ascensão de um número significativo de dirigentes da central a importantes cargos internacionais, em que se sobressaio caso de João Felício, ex-presidente da CUT alçado ao cargo de presidente da Confederação Sindical Internacional (CSI) no ano de 2014.Esses são pontos referenciais para o caso analisado a seguir, em que tratamos das trajetórias de inserção internacional dos 
sindicalistas brasileiros Fernando Lopes e Valter Sanches ${ }^{9}$ na Federação Internacional dos Trabalhadores nas Indústrias Metalúrgicas (FITIM) que, em 2012, passa a se chamar IndustriALL.

\section{Entre o global e o local: a ascensão de lideranças brasileiras às organizações sindicais internacionais}

Entre os dias 3 e 7 de outubro de 2016, a IndustriALL Global Union realizou, no Rio de Janeiro, seu segundo congresso, no qual um metalúrgico brasileiro foi eleito secretário geral da entidade: Valter Sanches, ex-secretário de Relações Internacionais da Confederação Nacional dos Metalúrgicos da CUT (CNM/CUT). Essa foi a primeira vez que um representante do hemisfério Sul alcançou o principal cargo da organização global. Na gestão anterior, Fernando Lopes, metalúrgico, também ex-secretário de relações internacionais da CNM/CUT, ocupou o cargo de secretário geral adjunto da entidade. Na atual direção, Sanches é o único metalúrgico brasileiro no Comitê Executivo da entidade, mas está acompanhado de Lu Varjão (presidente da Confederação Nacional dos Químicos/CUT), eleita para o Conselho Diretivo da IndustriALL.

A IndustriALL Global Union conta com mais de 600 sindicatos filiados em 140 países e defende a solidariedade mundial na luta por melhores condições de trabalho e a garantia do direito de organização sindical dos trabalhadores. Essa FSI multissetorial, fundada em 2012, é o resultado da fusão de organizações como a FITIM, a Internacional dos Trabalhadores Químicos, da Celulose, da Energia, Mineração e Indústrias Diversas (ICEM),

\footnotetext{
${ }^{9}$ É importante observar que as trajetórias sindicais selecionadas para este artigo, apesar de paradigmáticas, por condensarem a incorporação de uma série de capitais simbólicos e disposições que se articularam a elementos de ordem contextual, não se tratam de casos isolados. Por exemplo, a trajetória do sindicalista metalúrgico Marino Vani, que ocupa cargo no escritório regional da IndustriALL, em Montevidéu, no Uruguai, não foi incorporada à análise apenas em razão das limitações de espaço deste artigo.
} 
e a Federação Internacional de Trabalhadores na Indústria Têxtil, Vestuário e Couro (FITTVC). O referido processo de unificação representou um importante reordenamento no ambiente das estruturas sindicais internacionais, dado que a IndustriALL se tornou a maior FSI do planeta, ultrapassando a UNI Global Union, que representa cerca de 20 milhões de trabalhadores dos setores de comércio, telecomunicações, finanças e outros.

Diante da tendência de expansão internacional de escopo da atuação dos sindicatos, uma pergunta importante para a compreensão das reconfigurações das entidades sindicais diz respeito a quais são os sindicalistas que vêm, paulatinamente, assumindo essas tarefas. Em outras palavras, é fundamental indagar quais são os perfis, atributos sociais e capitais culturais e políticos exigidos dessas lideranças nas diferentes "frentes" de ação sindical. No caso da circulação internacional, faz-se necessário ainda analisar quais são as condições sociais que permitem o entendimento e a assimilação das regras de um novo espaço de ação política perpassado por diferentes tradições sindicais e contextos em que se desenvolvem a regulação das relações de trabalho.

Apoiados sobre a necessidade de se construir uma agenda global de luta em defesa dos direitos dos trabalhadores, alguns sindicalistas foram capazes de alcançar cargos estratégicos no plano internacional. A análise dessas trajetórias aponta para elementos que as diferenciam significativamente da maioria das lideranças da categoria metalúrgica no Brasil, tais como (i) a origem social em grupos médios com maior escolarização; (ii) a posse de títulos escolares valorizados, expedidos por instituições de ensino superior; (iii) o domínio de, no mínimo, um idioma estrangeiro e (iv) um engajamento político que se inicia no movimento estudantil, passando por organizações de esquerda para, posteriormente, se converter em militância sindical (Rombaldi, 2012, 2016; Tomizaki, 2013a; 2013b). Esse conjunto de experiências tornou possível a formação de um 
habitus militante que, no contato com o campo sindical internacional, desdobrou-se em "competências" que se materializam em determinadas práticas e discursos, permitindo a esses sindicalistas: (i) valorizar e investir na atuação no âmbito internacional; (ii) compreender a dinâmica das estruturas sindicais internacionais; (iii) desvendar o funcionamento das organizações financiadoras de projetos de cooperação sindical internacional, bem como o funcionamento das iniciativas implementadas pelas $\mathrm{FSIs}^{10}$; (iv) e construir um "espaço de legitimidade" para sua atuação, mediante o reconhecimento (nacional) de sua habilidade para representar sua categoria internacionalmente. A seguir, por meio da análise das biografias, discutiremos a formação e o funcionamento desse habitus militante.

\section{Entre o nacional e o internacional: duas trajetórias exemplares}

Fernando Lopes nasceu em 1960, na cidade de Pinheiro (MA), filho de um dentista e de uma assistente social, e formou-se engenheiro mecânico em 1985, pela Universidade Estadual do Maranhão (UEMA). Iniciou suas atividades políticas em 1974, no movimento estudantil e, cinco anos depois, tornou-se militante da Organização Revolucionária Marxista - Política Operária (POLOP) no congresso de refundação da União Nacional dos Estudantes (UNE). Fernando afirma que nunca se afastou da POLOP como tendência política, mas ao longo dos anos 1990 ela deixou de funcionar, momento em que ele passou a militar exclusivamente no PT, partido cuja fundação foi apoiada pela organização marxista. Até os dias atuais, ele atua no Centro de Estudos Victor Meyer, que reúne os militantes da POLOP e tem como um dos seus principais objetivos contri-

\footnotetext{
${ }^{10}$ As FSIs são financiadas, majoritariamente, por meio de dois canais. Em primeiro lugar, estão as contribuições provenientes de cotas de filiação de entidades nacionais. Em segundo, estão os recursos provenientes de projetos estabelecidos em parceria com organizações cooperantes de países desenvolvidos. Negociações sobre conteúdo, aprovação, execução e valores de projetos são, portanto, atividades fundamentais à sobrevivência das federações.
} 
buir para a recuperação e preservação das lutas operárias e da esquerda revolucionária no Brasil.

Fernando foi eleito Diretor do Sindicato dos Engenheiros do Maranhão na gestão de 1986/1989. Em 1987, mudou para Salvador e passou a exercer a função de engenheiro na Usiba-Gerdau, onde foi rapidamente eleito para a Comissão Interna de Prevenção de Acidentes de Trabalho (CIPA). Em 1991, ele assumiu o cargo de Diretor do Sindicato dos Metalúrgicos da Bahia, dando continuidade à sua trajetória política no meio sindical.

De acordo com Fernando, a colaboração entre o movimento sindical brasileiro e o movimento internacional se intensificou durante a luta contra a ditadura militar. Efetivamente, durante a 1a Conferência Nacional das Classes Trabalhadoras (CONCLAT), em 1981, várias delegações sindicais estrangeiras estiveram presentes ${ }^{11}$ e, em conjunto com lideranças brasileiras empregadas em empresas de origem europeia com tradição organizativa sindical, influenciaram a criação da Secretaria de Relações Internacionais dentro da estrutura que se formaria com o nascimento da CUT, dois anos mais tarde. Principalmente, nas palavras de Fernando, nesse momento, passou-se a "incorporar no programa político cutista a importância da internacionalização das lutas". Além disso, Fernando observa que sindicalistas brasileiros exilados na Europa trouxeram, no seu retorno ao Brasil, redes de relações com sindicatos de diferentes países (cf. Chotil, 2015).

Segundo o sindicalista, sua relação com o sindicalismo internacional teve início na Gerdau, nos anos 1990, em função do processo de formação do Comitê Mundial de trabalhadores dessa ETN, impulsionado no primeiro encontro da rede de trabalhadores no Primeiro Fórum Social Mundial, no ano 2001, em Porto Alegre. No início dos anos 2000, após

\footnotetext{
${ }^{11}$ Conforme documento da CUT intitulado "A política internacional da CUT: histórias e perspectivas".
} 
ter participado da primeira diretoria da CNM-CUT, de 1995 a 2001, Fernando foi eleito Secretário Geral da CNM/CUT, e passou a ser responsável, também, pelas relações internacionais da entidade. Isso the permitiu circular em outras esferas, até ser eleito para o Comitê Executivo da FITIM, em 2003. De acordo com seu depoimento, até aquele momento, a FITIM contava com um secretário geral oriundo de um país desenvolvido que atuava em conjunto com um secretário adjunto, representante de país em desenvolvimento. Ao longo de sua gestão na FITIM o secretário adjunto da África se aposentou, o que precipitou sua indicação para o cargo.

Vale destacar que, embora já houvesse, desde a formação da CUT, um movimento em direção à internacionalização da militância, durante os anos 1990 o setor metalúrgico foi marcado por uma crise econômica que redundou na ampliação e alteração do escopo de atuação dos sindicatos dessa categoria. Nesse momento, a importância da internacionalização das lutas sindicais se consolidou, sobretudo, em função da necessidade de negociar com as ETNs. Em especial, Fernando relata que surgia o entendimento de que as lideranças metalúrgicas "deveriam se internacionalizar" a partir "da melhoria dos perfis e das habilidades" sindicais, o que significava, entre outras coisas, uma crescente exigência de maior escolaridade e domínio de línguas estrangeiras.

Foi nesse período que a CNM passou a incentivar os seus dirigentes a estudar idiomas estrangeiros, por meio de cursos oferecidos pela confederação e de viagens de intercâmbio. Essas viagens eram organizadas junto a sindicatos estrangeiros, que receberam Fernando e outros sindicalistas - em um acordo em que as organizações de fora do país financiariam a hospedagem e o curso de idiomas, enquanto a confederação brasileira custearia passagens aéreas e as diárias do participante. A experiência de Fernando foi junto à Canadian Autoworkers Union, do Canadá, na 
qual ele aprimorou suas habilidades em inglês - já existentes desde os tempos em que estudou engenharia- durante um curso de formação sindical proposto pelo sindicato que o hospedou. Fora do período de intercâmbio, ele afirmou que, por meio de atividades sindicais internacionais da confederação, ainda chegou a desenvolver o aprendizado do espanhol, do italiano e do francês, que, afirma, "dão para o gasto".

A CNM, portanto, mostrou-se um catalizador para a internacionalização de dirigentes sindicais. A rede de contatos estabelecida junto a sindicatos de outros países serviu não apenas para um certo tipo de sociabilização internacional das lideranças locais, já que impulsionou o seu trânsito fora do país, mas também para a promoção de um savoir-faire sobre a captação e execução de projetos globais que seriam desenvolvidos no Brasil em parceria com organizações cooperantes estrangeiras. A partir dos anos 2000, além de participar dos espaços promovidos pela FITIM, por meio de relações estabelecidas diretamente com organizações sindicais de diversos países como IF Metall/Suécia, CAW/Canadá, FM-CCOO/Espanha, USW/EUA-Canadá, AFL-CIO/EUA e FES/Alemanha, a CNM desenvolveu uma série de projetos de cooperação de organização sindical em temas como juventude, raça e gênero, bem como buscou consolidar-se no campo internacional por meio da promoção de ações voltadas à inovação sindical, tais como os projetos para a construção de redes em ETNs (Rombaldi, 2016).

Embora na primeira década do novo século os quadros sindicais metalúrgicos já estivessem formados e inseridos em espaços internacionais estratégicos, é inegável, segundo Fernando, que o governo Lula deu grande visibilidade ao Brasil no exterior:

...as políticas de emprego, renovação do setor naval, políticas de inclusão tiveram um grande efeito internacional, todos queriam saber como funcionava o fome zero, como eram as políticas de inclusão. [...] Nos 8 anos de Lula e os 4 
primeiros de Dilma foram tranquilos pra nós, o Brasil estava indo bem, os empregos surgindo, salários aumentando, o salário mínimo aumentando acima da inflação, até 2014 todas as categorias fecharam acordos com aumentos salariais acima da inflação.

Além disso, cabe destacar que, naquele período, o governo brasileiro passava a ser marcado pela trajetória de ascensão política de um ex-dirigente sindical metalúrgico que não apenas chegara à presidência, mas também havia sido reeleito e alcançaria, ao final do seu segundo mandato, $87 \%$ de aprovação ${ }^{12}$.

Fernando, que, no momento da última entrevista, aguardava a posse de Sanches na IndustriALL para tomar conhecimento quanto ao espaço que ainda ocuparia na federação, acredita que o impeachment da presidenta Dilma Rousseff, a implementação de políticas de austeridade fiscal e os ataques aos direitos trabalhistas devem conduzir a uma maior concentração de tempo e energia dos sindicatos nacionais em uma agenda de luta local:

[...] não há braços e pernas para tudo, também será preciso direcionar os recursos para as lutas nacionais, os quadros também terão que ficar mais no Brasil, mas a influência e espaço continuarão os mesmos, por outro lado, haverá de novo grande interesse em torno do que ocorre no Brasil. A agenda positiva ajudou na internacionalização, a agenda regressiva faz os esforços ficarem mais concentrados no nacional.

Valter Sanches é outro exemplo de sindicalista que ascendeu a importantes espaços no sindicalismo internacional. Nascido em 1964, em Loanda (PR), sua família migrou do interior do estado de São Paulo em direção ao Paraná no início da década de 1960, atraída pelas oportunidades de emprego abertas pela expansão cafeeira. Seu pai era contador

\footnotetext{
12 Acessado em http://g1.globo.com/politica/noticia/2010/12/popularidade-de-lula-bate-recorde-e-chega-87-diz-ibope.html, 13/12/2016.
} 
e, no novo estado, investiu na formação de um pequeno escritório de contabilidade que prestava serviços a torrefações e outros estabelecimentos ligados ao cultivo e comércio do café. O refluxo desse setor, no final daquela década, levou o escritório à falência e provocou o retorno da família ao estado de São Paulo.

Sanches passou a maior parte de sua escolarização na Escola de Aplicação da Faculdade de Educação da USP, na qual ingressou por meio do sorteio de vagas para a comunidade. Do período escolar, Sanches declara guardar marcantes lembranças da repressão que se abatia sobre toda a Universidade de São Paulo e também sobre a Escola de Aplicação, que seria a raiz do seu engajamento político e do interesse pelo movimento dos metalúrgicos do $\mathrm{ABC}$.

Durante o antigo "segundo grau", Sanches perdeu seu pai, o que colocou a família em uma situação financeira bastante vulnerável e precipitou seu ingresso no mercado de trabalho, aos 16 anos, como office-boy, fortalecendo a necessidade de profissionalização para o trabalho, concretizada pelo curso de mecânica em uma Escola Estadual Técnica, onde iniciou sua militância política, seguindo os passos da irmã mais velha, que já militava no movimento estudantil secundarista e no PT, mais especificamente, na corrente "O Trabalho".

Em 1985, quando começou a trabalhar no ABC Paulista, Sanches já cursava geografia na USP, no período noturno, e rompeu com a corrente "O Trabalho". Segundo seu depoimento, tal rompimento se deveu ao crescente envolvimento com o movimento sindical e com o trabalho na fábrica. Durante o movimento estudantil, diz ele, era tudo teórico. Depois, ele recorda que começou a enfrentar dificuldades para relacionar uma perspectiva revolucionária comas demandas mais concretas e imediatas da militância sindical. No mesmo sentido, passou a discordar das interpretações de sua corrente política a respeito da atuação de Lula 
e de outras lideranças sindicais do ABC, considerados por ela como "neo-pelegos" que "acabariam por trair toda a classe trabalhadora brasileira".

Na Mercedes-Benz, Sanches ocupava um posto técnico, na área de planejamento da produção. Em 1989 disputou sua primeira eleição para representação dos trabalhadores, e pode, na primeira década como sindicalista, assistir a transformações profundas nas relações entre movimento sindical e as empresas:

Foram mudanças de ambos os lados, não foi só da nossa parte. Eu acho que do nosso lado melhorou muito: compreender melhor o processo, compreender além dos muros da fábrica, em termos de categoria, de país, compreender a cadeia de fornecimento, os problemas políticos, a conjuntura econômica do país [...]. [Sobre a reestruturação produtiva] tivemos que aprender na raça, com o negócio acontecendo, tendo que investir, tendo que conquistar o espaço pra negociar! E isso foi um processo de formação muito intenso! Foi complicado... Viagens internacionais, o Dieese trabalhou muito nisso, também.

Assim como no caso de Fernando Lopes, Sanches também desenvolveu sua trajetória em direção ao sindicalismo internacional em função de trabalhar em uma ETN que, como a Gerdau, conta com uma organização mundial de trabalhadores. A empresa também foi marcada pelo processo de reestruturação produtiva que, nos anos 1990, abriu uma nova fase na relação dos trabalhadores da Mercedes-Benz do Brasil com os seus colegas da matriz na Alemanha. Nesse contexto, observa-se que, dos anos 1980 até meados da década de 1990, as relações entre trabalhadores das empresas dos dois países foram marcadas essencialmente por atos de solidariedade, visitas de ambas as partes e troca de informações.

Foi somente durante o processo de reestruturação produtiva levado a cabo pela Mercedes-Benz do Brasil, no entanto, que esses dois grupos iniciaram um processo intenso de troca de experiências e debates sobre 
os rumos da empresa (Rodrigues, 2014). Vale destacar que parte desse contato inicial foi estimulada pela própria direção da Mercedes Benz do Brasil (MBB), que pretendia "apresentar" aos trabalhadores brasileiros as "vantagens" da reestruturação já ocorrida na Alemanha. Foi quando a empresa se ofereceu para custear um curso de alemão para um dos sindicalistas e, como Sanches já dominava o inglês, foi indicado pela comissão de fábrica para estudar, também, a língua alemã. $O$ aprendizado de idiomas, de fato, se já se mostrava uma característica distintiva e permanente do percurso social de Sanches que, atualmente, domina também o francês e espanhol. Sanches foi um dos sindicalistas, assim como Fernando, que se beneficiou de sua escolaridade muito mais alta do que a média dos trabalhadores do setor metalúrgico, além do imprescindível domínio de uma língua estrangeira para disparar sua inserção no sindicalismo internacional.

No primeiro semestre de 2007, depois de coordenar a Comissão de Fábrica e o Comitê Sindical de Empresa na MBB, e de representar o Brasil no Comitê Mundial dos Trabalhadores da Daimler Chrysler, Sanches assumiu um assento no Conselho Mundial de Administração da Daimler (CMAD), o qual foi criado em função de uma lei alemã de 1972, que determinou a constituição de um conselho de administração paritário que reunisse representantes dos proprietários ou acionistas e representantes dos trabalhadores em todas as empresas com mais de 200 empregados. O CMAD, que se reúne a cada dois meses, tem o papel de fiscalizar a atuação da diretoria executiva das empresas do grupo, designar ou desligar diretores, aprovar planos de investimento, aportes de capital, fusões, vendas, aquisições ou encerramento de atividades de plantas produtivas. A experiência de participação nesse espaço permitiu a Sanches adquirir novos e aprofundados conhecimentos sobre o funcionamento e a administração das ETNs, bem como sobre a elaboração de estratégias sindicais 
neste espaço de atuação. Posteriormente, o sindicalista substituiu Fernando na Secretaria Geral da CNM/CUT e assumiu a secretaria de Relações Internacionais da confederação. Em dezembro de 2009, Sanches deixou a secretaria geral, mas continuou como secretário de Relações Internacionais da confederação. Em dezembro de 2016, depois de coordenar o setor de comunicação do Sindicato dos Metalúrgicos do ABC, Sanches foi indicado pelo IGMettal, da Alemanha, como candidato ao cargo de secretário geral da IndustriALL, sendo eleito no congresso de dezembro de 2016, após receber o apoio dos principais atores políticos desta FSI.

Tal apoio à candidatura de Sanches foi constituído, assim, a partir de uma dimensão que articula as experiências individual e coletiva. De um lado, certas competências haviam sido adquiridas na passagem pelo Conselho de Administração da Daimler e atestavam virtudes deste brasileiro quanto às demandas requeridas no exercício da militância internacional. A esse respeito, o próprio sindicalista reconhece que a IndustriALL, de certa forma, pode ser considerada uma "pequena empresa multinacional" por contar com aproximadamente 40 funcionários na sede em Genebra e outros 29 distribuídos nos 13 escritórios de diferentes países. De outro, o apoio ao dirigente mostrou-se relacionado à sua trajetória no interior da CUT, uma central sindical latino-americana reconhecida e apoiada por lideranças europeias desde o seu nascimento, no começo da década de 1980, durante a ditadura civil-militar vivenciada no Brasil. Aqui, outra variável significativa refere-se ao fato de que o processo de ascensão de Sanches ao mais alto posto da hierarquia da IndustriALL ocorreu após um contexto em que, conforme observado, Lula havia ganhado destaque no exterior como experiência de governo democrático-popular. Nesse sentido, portanto, o espaço ocupado por brasileiros no movimento sindical internacional se mostra como resultado da convergência entre diferentes fatores: a formação de quadros qualificados para tarefas internacionais, 
os resultados dos investimentos da CNM/CUT na formação de redes de solidariedade sindical e a projeção de sindicalistas brasileiros no exterior.

\section{Habitus militante e circulação internacional: considerações finais}

A circulação internacional constitui uma estratégia importante para diversos grupos dirigentes ao longo do tempo. Isso não foi diferente entre as elites políticas, que também se beneficiaram de capitais "adquiridos" por meio do acesso a espaços internacionais, bem como da assimilação de agendas e práticas políticas específicas (Canêdo, 2013; Dezalay, 2004). No campo sindical, não foi diferente: a circulação internacional garantiu a algumas lideranças um lugar de destaque no campo sindical nacional, na medida em que essas representavam, nacionalmente, a necessária construção de uma agenda de luta sindical global e, internacionalmente, os trabalhadores de um dos mais importantes países em desenvolvimento. Neste artigo, apresentamos duas trajetórias exemplares do ponto de vista da constituição de um habitus militante específico que, em razão de responder às expectativas e exigências do espaço sindical internacional, Ihes ampliou as condições de inserção e ascensão a posições de destaque, até então improváveis às lideranças brasileiras.

A análise dos dados apresentados no artigo nos permite afirmar que os sindicalistas que circulam internacionalmente o fazem por conta da confluência entre fatores objetivos e subjetivos. Provenientes de um sindicalismo cutista "aberto" ao espaço internacional e contextualizado num período em que o movimento sindical brasileiro ganhou visibilidade no exterior por meio do governo Lula, as lideranças analisadas tiveram o seu trânsito internacional potencializado pela posse de determinados capitais simbólicos fortemente associados à sua origem social - mas que não 
necessariamente coincidem com os atributos necessários para se estabelecer como liderança no plano local. O habitus militante que legitima a atuação dos sindicalistas analisados se mostrou fundado sobre competências e disposições tidas como fundamentais para a condução de tarefas internacionais: o domínio de língua estrangeira, o entendimento sobre o funcionamento das estruturas sindicais internacionais, apreendido por meio de atividades desempenhadas no plano nacional, a compreensão sobre os mecanismos de negociação junto a ETNs, e a habilidade para "circular" entre entidades e lideranças com posições e práticas políticas nem sempre convergentes.

Destaca-se ainda que, para além das evidentes proximidades no que tange à origem social e consequente oportunidade de alongamento da escolarização - que produziu efeitos permanentes sobre as condições de desenvolvimento das carreiras dos sindicalistas analisados -, é preciso considerar o fato de assuas trajetórias militantes terem se iniciado em organizações/correntes políticas de extrema esquerda, que valorizavam a internacionalização da luta operária. Essa formação, conjugada com a aquisição de determinados capitais simbólicos, incentivou e facilitou a circulação internacional, por propiciar a constituição de disposições ajustadas a este campo político.

Com isso, a análise das trajetórias sociais apresentadas buscou contribuir com o entendimento de particularidades do sindicalismo brasileiro, em suas experiências individuais e coletivas. Visou, também, a lançar luz sobre um leque de possibilidades de pesquisa no âmbito da sociologia do trabalho, principalmente no que se refere às organizações sindicais internacionais, suas relações com entidades nacionais e suas lideranças. Se, conforme sublinhamos, as prioridades dadas a ações de caráter doméstico-nacional podem atuar como freio à internacionalização das práticas sindicais, o acesso de brasileiros a altos cargos da hierarquia sindical inter- 
nacional pode estar sinalizando, silenciosamente, para um futuro rearranjo nas lógicas de atuação sindical, no perfil de dirigentes e na primazia de determinadas agendas políticas.

Maurício Rombaldi é Doutor em Sociologia pela Universidade de São Paulo e Professor Adjunto da Universidade Federal da Paraíba (UFPB).

$\triangle$ Mmauricio.rombaldi@gmail.com

Kimi Aparecida Tomizaki é Doutora em Educação pela UNICAMP e Professora de sociologia na FE/USP, junto ao Departamento de Filosofia e Ciências da Educação (EDF) e ao Programa de Pós-graduação em Educação.

\kimi.tomizaki@gmail.com

\section{Referências}

1. BEAUD, S.; PIALOUX, M. Retorno à condição operária. Investigação em fábricas da Peugeot na França. São Paulo: Boitempo, 2009.

2. BOLTANSKI, L.; CHIAPELLO, È. O novo espírito do capitalismo. São Paulo: Martins Fontes, 2009.

3. BOULLAND, P. "Des hommes quelconques"? La politique d'encadrement au crible de la sociobiographie (1994-1974). In: PENNETIER, C.; PÙDAL, B. Le sujet communiste. Identités militantes et laboratories du "moi". Rennes: Presses Universitaires de Rennes, 2014.

4. BOURDIEU, P. L'illusion biographique. Actes de la recherche en sciences sociales. v. 62-63, 1986, p. 69-72.

5. BOURDIEU, P. A representação política. Elementos para uma teoria do campo político. In: BOURDIEU, P. O poder simbólico. Rio de Janeiro: Bertrand Brasil, 2005

6. BOURDIEU, P. O senso prático. Rio de Janeiro: Vozes, 2009.

7. CANÊDO, L. B. Herdeiros, militantes, cientistas políticos: socialização e politização dos grupos dirigentes no Brasil. In: CANÊDO, L.; TOMIZAKI, K.; GARCIA Jr., A. (Orgs.). Estratégias educativas das elites brasileiras na era da globalização. São Paulo: Hucitec Editora/FAPESP, 2013. 
8. CHOTIL, M. T. L'exil ouvrier. La saga dès brésiliens contraints au départ (19641985). Paris: Éditions Estaimpuis, 2015.

9. COSTA, H. A. O Sindicalismo, a política Internacional e a CUT. Revista Lua Nova, n. 64, 2005.

10. DEZALAY, Y. Les courtiers de l'international. Actes de la recherche en sciences sociales, n. 151-2, mar 2004, p. 4-35.

11. EVANS, P. Is it Labor's Turn to Globalize? Twenty-first Century Opportunities and Strategic Responses. Global Labour Journal, v. 1, n. 3, 2010, pp. 9-27.

12. FILLIEULE, O.; PUDAL, B. Sociologie Du militantisme : problématisations et déplacement des méthodes d'enquête. In : FILLIEULE, O.; AGRIKOLIANSKY, E.; SOMMIER, I. Penser mouvements sociaux. Conflits sociaux et contestations dans lês sociétés contemporaines. Paris : La Découverte, 2010

13. HARVEY, D. Condição Pós-Moderna. São Paulo, Loyola, 1993.

14. LECLERCQ, C.; PAGIS, J. Les incidences biographiques de I'engagement. Socialisations militantes et mobilité sociale. Sociétés contemporaines, n. 84, 2011/4, p. 5-23.

15. MATONI, F.; POUPEAU, F. Le capital militant. Essai de définition. Actes de la Recherche - Le capital militant : engagements improbables, apprentissages et techniques de lutte. n. 155, dezembro, 2004

16. MELLO e SILVA, L.; FRAMIL FILHO, R.; FRESTON, R. Redes sindicais em empresas transnacionais: enfrentando a globalização do ponto de vista dos trabalhadores. Publicação da Fundação Friedrich Ebert Stiftung Brasil, número 5, 2015. Disponível em: http://library.fes.de/pdf-files/bueros/brasilien/12011.pdf. Acesso em 1을 2016.

17. MUNCK, R. P. Globalization and the Labour Movement: Challenges and Responses. Global Labour Journal, v. 1, n. 2, 2010, pp. 218-232.

18. PETERS, G. Configurações e reconfigurações na teoria do habitus: um percurso. XIV Congresso Brasileiro de Sociologia. (GT 29 - Teoria Sociológica), Rio de janeiro, 28 a 31 de julho, 2009.

19. PRIES, L.; SEELIGER, M. Work and Employment Relations in a Globalized World: The Emerging Texture of Transnational Labour Regulation. Global Labour Journal, v. 4, n. 1, 2013, pp. 26-47.

20. RAMALHO, J. R. Trabalho, sindicato e globalização. Política \& Trabalho, n. 41, out de 2014, pp. 25-43.

21. RODRIGUES, E. M. A organização internacional dos trabalhadores metalúrgicos na Mercedes-Benz do Brasil: perspectivas de contra-hegemonia local-global. Revista ciências do trabalho, n. 2, maio/out 2014, pp. 21-44. 
22. ROMBALDI, M. Internacionalização do sindicalismo no Brasil: um estudo sobre os setores metalúrgico e de telecomunicações. Tese de doutorado, São Paulo, USP, 2012.

23. ROMBALDI, M. A Copa de 2014 e os trabalhadores da construção: estratégias globais, mobilizações locais. Revista da ABET, v. 13, p. 184-198, 2014.

24. ROMBALDI, M. Diferentes ritmos da internacionalização sindical brasileira: uma análise dos setores metalúrgico e de telecomunicações. Caderno $\mathbf{C R H}$, Salvador, v.29, n.78, pp. 535-51, set/dez. 2016.

25. TOMIZAKI, K. Internacionalismo operário e socialização política de dirigentes sindicais. In: CANÊDO, Letícia; TOMIZAKI, Kimi; GARCIA Jr., Afrânio. (Orgs.). Estratégias educativas das elites brasileiras na era da globalização. São Paulo: Hucitec Editora/FAPESP, 2013a.

26. TOMIZAKI, K. Deux générations de syndicalistes au Brésil : pratiques quotidiennes et formation politique. Actes de la recherche en sciences sociales, v. 196-197, p. 102-113, 2013b.

27. TOMIZAKI, K.; ROMBALDI, M. Construindo a legitimidade: reflexões sobre as transformações das práticas de militância no movimento sindical. Pro-Posições, v. 20, p. 93-112, UNICAMP, 2009.

28. UNCTAD. World Investment Report 2008: Transnational Corporations and the Infrastructure Challenge. UNCTAD, 2008.

Recebido em: 19.01.2017

Aceite final: 05.04.2017 